\title{
DIÁLOGOS ENTRE HISTÓRIA E PSICOLOGIA: A BIOGRAFIA NA BERLINDA
}

\author{
Flávia Cristina Silveira LEMOS ${ }^{1}$ \\ Universidade Federal do Pará \\ flavialemos@ufpa.br
}

\begin{abstract}
Resumo: Pretende-se, neste texto, interrogar os usos da biografia e da autobiografia, pensando os efeitos desta prática de produção de si, a partir de discussões baseadas em Foucault e Bourdieu. Diversos autores, representantes das ciências sociais e humanas, têm assinalado o interesse crescente pelo tema, na atualidade. A biografia e a autobiografia podem ser utilizadas para a construção de um modelo exemplar a ser imitado e canonizado, produzindo uma concepção de unidade, linearidade, sentido e continuidade na história de vida, contudo, também possibilita rupturas com a mesma, dependendo do modo como for utilizada. Deste modo, a teoria da história teria contribuições para as práticas da Psicologia, a partir de um diálogo a respeito da temática e discussão em pauta.
\end{abstract}

Palavras-chave: Biografia. Autobiografia. História de vida.

Summary: She pretends - if, this text, interrogate the uses from biography and from autobiography, wondering the outcomes from this practice of production of oneself, as of this date discussions based in Foucault and Bourdieu. Diverse authors, representatives from the social sciences and humans, they have checkmark the interest crescent at theme, on actuality. The biography and the autobiography can be used for building by one model exemplary the be imitator and canonize, producing a conception of unit lineality, grieved and continuance on history of life, all the same, also allow rupture with the uniformity, depending on the manner I eat if he may be used. In this way, the theory from history he should be contributions about to the practices from Psychology, from one dialog the respect from thematic and discussion in rule.

Keywords: Biography. Autobiografhy. History of life.

Pretende-se neste artigo realizar uma discussão, no campo das pesquisas historiográficas e no debate da teoria da história a respeito dos usos da biografia e da autobiografia.

Nos últimos anos, haveria de acordo com Gomes (2004), uma intensa publicação de caráter biográfico e autobiográfico. Tratar-se-ia de um gênero específico, denominado escrita de si. "Cartas, diários íntimos e memórias, entre outros, sempre tiveram autores e leitores, mas na última década, no Brasil e no mundo, ganharam um reconhecimento e uma visibilidade maior tanto no mercado editorial, quanto na academia” (GOMES, 2004, p. 08).

Fraiz (1988) assinala que o gênero autobiográfico nasce juntamente com a emergência do indivíduo, durante o Renascimento. A partir do século XIX e, especialmente do XX, há um aumento vertiginoso da preocupação com as autobiografias. Simultaneamente

\footnotetext{
${ }^{1}$ Psicóloga/UNESP, Mestre em Psicologia e Sociedade/UNESP, Doutora em História e Sociedade/UNESP; Professora Adjunta em Psicologia Social da Universidade Federal do Pará.
} 
ao aparecimento da autobiografia, há o surgimento dos arquivos pessoais, passamos a arquivar nossas vidas. Aquele que não organiza seus papéis torna-se "anormal". O indivíduo perigoso, de acordo com Artières (1988), é aquele que foge a esse sistema de produção de si.

Este processo teria relação com os mecanismos de intimização na sociedade ocidental e a emergência do modo indivíduo. É com o nascimento do indivíduo, que passamos a nos preocupar em narrar minúcias do cotidiano. O mundo privado e intimista a que estamos tão acostumados nasce junto com o indivíduo, na modernidade. A curiosidade em tornar público o mundo privado só pode ter importância à medida que nos afastamos da esfera pública e passamos a cultivar a privacidade (SANTI, 1998).

O advento do romantismo, no início do século XVIII, de acordo com Santi (1998), teria potencializado a introspecção e cultivo de um intimismo e de um individualismo exacerbado. As diferenças entre os indivíduos passam a ser explicitadas e valorizadas, ancoradas no conceito de liberdade de ser e escolher um projeto para si.

o fato de que a vida constitui um todo, um conjunto coerente e orientado, que pode e deve ser apreendido como expressão unitária de uma intenção subjetiva e objetiva, de um projeto: a noção sartriana de projeto original somente coloca de modo explícito o que está implícito nos já, desde então, desde pequeno etc. das biografias comuns ou nos sempre (sempre gostei de música) das histórias de vida. Essa vida organizada como uma história transcorre, segundo uma ordem cronológica que também é uma ordem lógica, desde um começo, uma origem, no duplo sentido de ponto de partida, de início, mas também de princípio, de razão de ser, de causa primeira, até seu término, que também é um objetivo (BOURDIEU, 1986, p. 184).

Áries (1981) também ressalta como, a partir do nascimento da modernidade, as famílias se retraem do ambiente comunitário e se fecham em suas casas, cultivando o intimismo e a privacidade. Até então, a vida familiar era aberta à comunidade e sofria influência direta desta em suas ações e relações. Foucault (1979) ressalta como a medicalização da família vai produzindo uma maior densidade das relações afetivas entre os membros desta instituição à medida que esta vai se reorganizando a partir das prescrições médicas, que lhe demandavam um afastamento da comunidade.

Paradoxalmente, juntamente ao processo de individualização intimista e de valorização da privacidade, emerge a sociedade capitalista industrial de cunho liberal, na transição do século XVIII para o XIX, onde cresce a demanda de homogeneização dos 
corpos, que deveriam se submeter às coerções sociais e a padrões fixos de vida, em um processo de normalização biopolítica, tal qual afirma Foucault (1999a). Assim, paralelamente à individualização, surge a exigência de totalização através da gestão das populações pelos Estados Modernos e pelo imperativo da proteção e cultivo da vida (FOUCAULT, 1979; 1988; 1999a).

A família medicalizada e medicalizante, no interior de práticas de governo da vida biopoder - se torna um agente privilegiado na produção de processos intimistas e de confissão de pequenas minúcias da vida privada aos médicos e trabalhadores sociais, bem como entre os seus próprios membros (FOUCAULT, 1979; 1988).

Conforme Foucault (1988; 1999b), também, com a emergência da sociedade disciplinar, antecedendo as tecnologias biopolíticas totalizadoras, individualizou-se os corpos, passando a gerir o cotidiano destes em detalhe. Criamos as liberdades com a Revolução Francesa e, simultaneamente, as disciplinas coercivas das mesmas liberdades. Para este autor, esta nova sociedade era nomeada como disciplinar porque individualizava os corpos a partir de normas sociais que funcionavam como padrões de comportamento comuns, mas criavam mecanismos de exame, vigilância, diferenciação, classificação e comparação dos indivíduos em função destas normas.

Os indivíduos avaliados como próximos aos padrões eram premiados em um sistema meritocrático, sendo recompensados e se tornando modelos a serem seguidos por aqueles que se distanciavam das normas (FOUCAULT, 1999b).

O gênero biográfico e autobiográfico nasce a partir do desejo de publicizar uma memória considerada privilegiada, que fosse produzida como um modelo de sucesso a ser seguido e venerado por grupos que desejavam encontrar uma cartilha de prescrições que os conduzissem a um lugar de ascensão social (ALBUQUERQUE JR., 1998). A criação da narrativa a respeito do gênio e do herói são os exemplos deste processo de produção de modelos a partir de uma história de vida que culminou, por etapas, em uma constância linear, atingindo um apogeu (NIETZSCHE, 2003).

O mundo social, que tende a identificar a normalidade com a identidade entendida como constância em si mesmo de um ser responsável, isto é, previsivel ou, no mínimo, inteligivel, à maneira de uma história bem construída [...] dispõe de todo tipo de instituições de totalização e de unificação do eu. A mais evidente é, obviamente, o nome próprio [...]. Por 
essa forma inteiramente singular de nominação que é o nome próprio, institui-se uma identidade social constante e durável, que garante a identidade do indivíduo biológico em todos os campos possiveis onde ele intervém como agente, isto é, em todas as suas histórias de vida possíveis. (BOURDIEU, 1986, p. 186).

É neste contexto que passamos a nos preocupar em arquivar a própria vida. Os arquivos pessoais tornam-se uma condição de existência para as classes mais abastadas, aparecem como status. Para as classes populares, se impõem, muitas vezes, via estabelecimentos de assistência e de punição, como Foucault destaca em Em defesa da sociedade (1999a.), em Vigiar e punir (1999b) e em A vida dos homens infames (2003).

Como Foucault se interessava em realizar uma história do presente enquanto ontologia histórica de nós mesmos, cartografando os mapas de configuração de uma determinada sociedade, apontando seus sistemas de coerção e as condições de ruptura com determinados modos de vida (MAIA, 2000), também, colocava em análise a escrita biográfica e autobiográfica como mecanismo de registro e sujeição da atualidade.

Sendo assim, a produção dos memoriais seriam práticas que dizem do modo do homem moderno subjetivar-se. Os álbuns de família, as cartas, os diários íntimos, os extratos bancários, os canhotos de cheque, a carteira de identidade, as pastas com diplomas, o currículo, os documentos como apólices de seguro e contratos bem guardados e organizados, a criação de páginas pessoais na internet, a assinatura pessoal indicando a autoria e uma suposta autenticidade e até mesmo uma instituição jurídica.

Assim o nome próprio é o suporte (somos tentados a dizer a substância) daquilo que chamamos de estado civil, isto é, desse conjunto de propriedades (nacionalidade, sexo, idade etc.) ligadas a pessoas às quais a lei civil associa efeitos jurídicos e que instituem, sob a aparência de constatá-las, as certidões de estado civil. Produto do rito de instituição inaugural que marca o acesso à existência social, ele é o verdadeiro objeto de todos os sucessivos ritos de instituição ou de nominação através dos quais é construída a identidade social: essas certidões (em geral públicas e solenes) de atribuição, produzidas sob o controle e com a garantia do Estado, também são designações rígidas, isto é, válidas para todos os mundos possíveis, que desenvolvem uma verdadeira descrição oficial dessa espécie de essência social, transcendente às flutuações históricas, que a ordem social institui através do nome próprio; de fato, todas repousam sobre o postulado da constância do nominal que pressupõem todos os atestados jurídicos que envolvem um futuro a longo prazo, quer se trate de certificados que garantem de forma irreversível futuro longínquo, como os contratos de crédito ou de seguro, quer de sanções penais, toda condenação 
pressupondo a afirmação da identidade para além do tempo daquele que cometeu o crime e daquele que sofre o castigo (BOURDIEU, 1986, p. 187).

Guardar e classificar nossas vidas tornou-se uma coerção (ARTIÈRES, 1988). Organizar e reorganizar papéis e guardá-los com cuidado aparece como uma prática obrigatória, natural e que permite construir uma biografia, como uma história narrada de uma maneira totalizante, como percurso de uma origem primeira em direção a um caminho reto para um progresso e uma "carreira de sucesso".

Larrosa (1999) destaca que, se observarmos as escolas, atualmente, há uma solicitação massiva dos professores de que os alunos falem e escrevam a respeito de sua vida pessoal: que contem como foi o final de semana, que falem da família e de seus gostos.

A escrita tornou-se um dispositivo importante de produção de uma subjetividade interiorizada e intimizada. As redações, os desenhos e as brincadeiras das crianças passaram a ser reveladores de uma suposta verdade interna, passaram a ser atividades solicitadas pelos professores e utilizadas para discussões e problematizações a respeito das identidades dos alunos e de suas diferenças. O aluno é convidado a realizar uma ascese onde deve não somente escrever sobre si, mas principalmente, avaliar-se com sinceridade antes de escrever (LARROSA, 1999).

Também passamos a confessar nossos pensamentos e ações a terapeutas e médicos, que esmiúçam nosso passado em anamneses infindáveis. A investigação da história de vida pelos peritos e especialistas parece buscar encontrar nesta história um sentido e uma causa primeira que explique o presente. Artières (1988) relata como pesquisadores têm usado a história de vida, em estudos do cotidiano de pessoas que convivem com o HIV/AIDS, em vários países, por exemplo, pedindo a estes que anotem minuciosamente seus atos em diários de campo para serem manuseados nos estudos sobre estratégias de gestão desta epidemia. Ora, Foucault (1979) já nos alertou que não há poder sem saber e saber sem relações de poder. Deste modo, a biografia e a autobiografia se tornaram dispositivos de confissão capturados em registros/arquivos que fabricam efeitos de poder e disparam a constituição de novos saberes e modos de viver.

Foucault $(1988 ; 2002)$ intitula este processo de dispositivo da confissão e relata que ele surge, primeiramente, no cristianismo, por volta do século XVI. Confessar a vida íntima era uma maneira de expiar os pecados, de libertar-se deles. Este agenciamento da confissão 
foi apropriado por médicos, psiquiatras e psicólogos, posteriormente. Confessar nossos segredos aos especialistas tornou-se natural e até uma imposição, na modernidade.

Tudo leva a crer que o relato de vida tende a aproximar-se do modelo oficial da apresentação oficial de si, carteira de identidade, ficha de estado civil, curriculum vitae, biografia oficial, bem como da filosofia da identidade que o sustenta, quanto mais nos aproximamos dos interrogatórios oficiais - cujo limite é a investigação judiciária ou policial -, afastando-se ao mesmo tempo das trocas íntimas entre familiares e da lógica da confidência que prevalece nesses mercados protegidos. As leis que regem a produção dos discursos na relação entre um habitus e um mercado se aplicam a essa forma particular de expressão que é o discurso sobre si; e o relato de vida varia, tanto em sua forma quanto em seu conteúdo, segundo a qualidade social do mercado no qual é oferecido - a própria situação da investigação contribui inevitavelmente para determinar o discurso coligido. Mas o objeto desse discurso, isto é, a apresentação pública e, logo, a oficialização de uma representação privada de sua própria vida, pública ou privada, implica um aumento de coações e de censuras específicas (das quais as sanções jurídicas contra as usurpações de identidade ou o porte ilegal de condecorações representam o limite). E tudo leva a crer que as leis da biografia oficial tenderão a se impor muito além das situações oficiais, através dos pressupostos inconscientes da interrogação (como a preocupação com a cronologia e tudo o que é inerente à representação da vida como história) e também através da situação de investigação, que, segundo a distância objetiva entre o interrogador e o interrogado e segundo a capacidade do primeiro para manipular essa relação, poderá variar desde essa forma doce de interrogatório oficial que é, geralmente sem que o saiba o sociólogo, a investigação sociológica até a confidência - através, enfim, da representação mais ou menos consciente que o investigado fará da situação de investigação, em função de sua experiência direta ou mediata de situações equivalentes (entrevista de escritor célebre ou de político, situação de exame etc.), e que orientará todo o seu esforço de apresentação de si, ou melhor de produção de si (BOURDIEU, 1986, p. 189).

$\mathrm{Na}$ Antigüidade, a escrita de si não era utilizada com este objetivo. Conforme Foucault (1992), a escrita era um exercício do pensamento que permitia a meditação. O autor nos fala de duas formas de escrita - os hyponnematas e as correspondências. Os hyponnematas eram usados como livros de vida, um guia para nos conduzirmos. "Neles eram consignadas citações, fragmentos de obras, exemplos e ações de que se tinha sido testemunha ou cujo relato se tinha lido, reflexões ou debates que se tinha ouvido ou que tivessem vindo à memória. Constituíam uma memória” (FOUCAULT, 1992, p. 135).

Os hyponnematas não eram diários íntimos ou instrumentos de ascese, tratava-se de um processo de constituição de si pautada em uma ética e não em expiação ou purificação da 
consciência. A leitura, associada à escrita era uma prática de si, somente a leitura sem escrita causaria uma dispersão intensa. Passar de um livro a outro provocaria falta de atenção, a escrita daria densidade à leitura, fixando-a.

Havia também uma preocupação com a heterogeneidade na escrita dos hyponnematas. Não se buscava constituir uma doutrina filosófica unitária, não havia o objetivo de esgotar a obra de um autor ou de uma escola específica. O importante era explorar domínios diferenciados de leitura e operar uma escrita como uma colcha de retalhos, montando um corpo múltiplo ao invés de fazer retratos. Uma segunda maneira de escrita seriam as correspondências.

Os hyponnematas poderiam ser usados em cartas enviadas a outras pessoas. A carta imprimiria uma ação em seu destinatário e no remetente, simultaneamente. "Escrever é pois, mostrar-se, dar-se a ver [...]. A carta proporciona um face-a-face" (FOUCAULT, 1992, p. 150). Entretanto, não é um mostrar-se de decifração de si, mas uma abertura ao outro. Entre os assuntos tratados, podemos destacar os relacionados à saúde e relatos do dia-a-dia.

As anotações de hoje têm um caráter mais intimista e confessional, passamos a valorizar a especulação da vida privada e produzir intensa visibilidade para nossos atos e pensamentos mais íntimos. Isto passou a ter valor de mercado expresso, por exemplo, nas revistas de fofoca, na venda crescente de livros biográficos e na produção de filmes temáticos da vida de homens e mulheres considerados célebres por seus feitos. Além do que, passamos horas falando de nossa vida pessoal para técnicos como os psicólogos e médicos. Também, confidenciamos minúcias de nossas vidas para amigos e parentes, sendo este ato, muitas vezes, uma imposição travestida de sentimentos de lealdade.

Se nas classes mais favorecidas, as histórias de vida ganharam uma determinada visibilidade política através de mecanismos específicos de confissão; nas classes mais desfavorecidas, elas foram capturadas por outros dispositivos, de acordo com Foucault (2003). Para ele, as vidas das populações pobres foram capturadas em discursos através da composição dos dossiês - em inúmeros relatórios, constando detalhes de acontecimentos considerados infames de certas populações que recorriam aos órgãos de assistência ou que eram denunciadas às instituições de correção e punição. Em A vida dos homens infames, 
Foucault (2003) afirma que, a partir do século XVII, o agenciamento religioso da confissão tornou-se também administrativo, aparecendo sob a forma de registros e não mais de perdão.

Se a vida dos heróis era narrada como uma memória a ser canonizada pelos seus grandes feitos; o cotidiano de populações pobres passava a ser registrado nos dossiês de instituições de controle social, por volta do século XVII com outros fins. Os pequenos desvios foram capturados em discursos que deram visibilidade para existências anteriormente sem memória (FOUCAULT, 1999a, 2003). Porém, trata-se de uma entrada na história através de uma memória considera infame e não do herói.

A história de vida das populações pobres passa a compor o material de arquivos de diversas instituições. O Poder Judiciário desloca sua preocupação do crime para o um suposto indivíduo criminoso, buscando recompor a história de vida deste suposto ser criminoso. A pergunta que se impõe, então, é: como se produziu o indivíduo criminoso? Foucault (1999; 2000; 2002) chama atenção para este processo de constituição do indivíduo criminoso, da preocupação da psicologia e da psiquiatria com esta subjetividade supostamente delinqüente. Segundo os peritos da norma, a delinqüência foi construída como uma carreira, como resultado da adição de pequenos desvios ao longo da vida, tendo na primeira infância um de seus momentos fundadores (FOUCAULT, 1999a).

Quais seriam as pequenas faltas que teriam conduzido um indivíduo à delinquiência é uma pergunta que estará presente no aparelho judiciário e nas instituições para-judiciárias. Foucault (1999a; 2002) assinala que a psiquiatria se ramifica cada vez mais, a partir do século XIX, entrando em diversas instituições sociais. A prática de curar "doenças mentais" vai para um segundo plano, comparada à nova missão da medicina - a gestão dos mínimos desvios de conduta, em uma tarefa preventiva, designada como proteção social.

Trata-se de administrar os menores desvios frente aos modelos de referência, tomados como regras naturais a serem seguidas. E quanto mais cedo, melhor. É desse modo que a infância é capturada pelos dispositivos médicos e psicológicos. A virtualidade das ações que podem ser classificadas como indicativas de uma posterior carreira de delitos contra a propriedade e de crimes contra a sociedade passa a ser gerida. Castel $(1981 ; 2005)$ apontou o modo como apareceu esta inflação de gestão técnica dos riscos, na modernidade, 
pautada mais no código normativo do que no jurídico e como ela tem se intensificado a partir das demandas por proteção social, na atualidade.

Os múltiplos olhares e lutas discursivas do direito e da medicina psiquiátrica para o "caso" Rivière é um exemplo desta entrada em cena da biografia e da Psiquiatria no campo jurídico. Foucault nos diz que quando o Poder Judiciário começa a se perguntar pelos motivos do crime, deixa de julgar o crime e passa a julgar o indivíduo criminoso. Inicia-se a busca infindável pela reconstituição da biografia do criminoso. Em que minúcias da história de vida do criminoso se encontrariam as explicações que justificariam o crime? O memorial de Rivière é analisado, repartido em séries e remontado ao sabor dos olhares que o capturam e o transformam em caso médico/peça de um processo. Trata-se de um período de máxima produção de visibilidade e dizibilidade. Imagens e enunciados, ancorados em uma extensão dos dispositivos de controle dos pequenos detalhes se intensificam.

Bourdieu (1986) levanta vários problemas relacionados à organização das biografias. A vida não seria um conjunto de acontecimentos lineares seqüenciais que teriam um começo e uma finalidade e que poderiam ser rastreados por um pesquisador ou jornalista. A vida não seria um todo coerente que poderia ser apreendida como expressão unitária. Até o romance pós-moderno teria questionado a visão de uma vida dotada de sentido e proposto a noção de descontinuidade, apesar de uma tradição literária continuar ancorada na estrutura anterior.

Quanto à biografia, Levi (1986, p. 169) coloca a questão: "pode-se escrever a vida de um indivíduo?" Para ele, há uma abertura entre a imposição de regras e o cumprimento das mesmas e, a biografia seria uma possibilidade de estudarmos a relação dos indivíduos com os sistemas normativos a partir da noção de descontinuidade. Os mecanismos de poder sempre deixariam margem para a resistência.

O projeto genealógico de Foucault pode nos auxiliar na empreitada de interrogar as práticas sociais, a partir de uma história do presente; realizando uma história da produção do indivíduo moderno, das práticas correlatas que sustentam o modo de ser indivíduo, podendo criar outros territórios de existência, sem intenção biográfica ou autobiográfica, pois a história, para Foucault, é descontínua e qualquer tentativa de relacionar acontecimentos de uma maneira causal-explicativa é puramente arbitrária (MARTON, 2001). 
A história de vida, assim como qualquer outra história não tem finalidade, o tempo não tem um sentido que segue um percurso em linha reta (MARTON, 2001), como querem os construtores de biografias e autobiografias. Este excesso de memória, na sociedade ocidental, é prejudicial à vida, como já nos alertou Nietzsche. A história nos serve para criticar os objetos considerados universais e naturalizados e não para congelar o passado ou venerar modelos do passado que permaneceriam como vestígios no presente. Logo, "forjar uma identidade, uma unidade e uma intenção para a vida é traduzir o desconhecido para o conhecido, uma tradução que nasce de uma busca que não é a de qualquer espécie de causa, mas de uma causa que tranqüilize, que alivie.” (MOSÉ, 2005, p. 35).

Confessar nossa história de vida, com intenção biográfica, buscando revelar a verdade de um modo de ser designado sujeito é uma tentativa de eliminar a dor do mundo e instaurar um lugar de segurança, no entanto, esta prática é datada e diz de um processo de objetivação e de subjetivação do homem, na modernidade, segundo Foucault (1999a).

\section{Referências}

AlbuQuerque Jr., D. M. Os maus costumes de Foucault. Pós-História, Assis, v. 6, p. $67-$ 86, 1998.

ARIÈS, P. História social da criança e da família. Rio de Janeiro: LTC, 1981.

ARTIÈRES, P. Arquivar a própria vida. Estudos históricos. Rio de Janeiro: FGV, (21), 1988.

BOURDIEU, P. A ilusão biográfica. Em: FERREIRA, M. de M.\&AMADO, J. (Orgs.) Usos e abusos da história oral. 2a ${ }^{\mathrm{a}}$ ed. Rio de Janeiro: FGV, 1986.

FRAIZ, P. A dimensão autobiográfica dos arquivos pessoais: o arquivo de Gustavo Capanema. Estudos Históricos. Rio de Janeiro: FGV, N. 21, 1988.

CASTEL, R. A gestão dos Riscos: da antipsiquiatria à pós-psicanálise. Rio de Janeiro: Francisco Alves, 1981.

A insegurança social. O que é ser protegido? Petrópolis: Vozes, 2005.

FOUCAULT, M. Microfísica do poder. Rio de Janeiro: Graal, 1979.

História da Sexualidade I: a vontade de saber. Rio de Janeiro: Graal, 1988.

A escrita de si. In: O que é um autor? Lisboa: Vega, 1992.

Em defesa da sociedade. São Paulo: Martins Fontes, 1999a.

. Vigiar e Punir: a história da violência nas prisões. Petrópolis: Vozes, 1999 b. 
Eu, Pierre Rivière, que degolei minha mãe, minha irmã e meu irmão. $6^{\mathrm{a}}$. ed. Rio de Janeiro: Graal, 2000.

Os Anormais. São Paulo: Martins Fontes, 2002.

. A vida dos homens infames. Em: Motta, M. B. de (org.) Michel Foucault: estratégia, poder-saber. (Coleção Ditos e Escritos - Vol. IV). Rio de Janeiro: Forense Universitária, 2003.

GOMES, A. de C. Escrita de si: escrita da história. Rio de Janeiro: FGV, 2004.

LARROSA, J. A construção pedagógica do sujeito moral. In: SILVA, T. T. da (Org.) Liberdades reguladas: a pedagogia construtivista e outras formas de governo do eu. $2^{\mathrm{a}}$. ed. Petrópolis: Vozes, 1999.

LEVI, G. Usos da biografia. In: FERREIRA, M. de M.\&AMADO, J. (Orgs.). Usos e abusos da história oral. $2^{\mathrm{a}}$. ed. Rio de Janeiro: FGV, 1986.

MAIA, C. A. A questão da Aufklärung: mise au point de uma trajetória. In: BRANCO, G. C.; PORTOCARRERO, V. (Orgs.). Retratos de Foucault. Rio de Janeiro: NAU, 2000.

MARTON, S. Extravagâncias: ensaios sobre a filosofia de Nietzsche. 2a . ed. São Paulo: Discurso Editorial e Unijuí, 2001.

MOSÉ, V. Nietzsche: e a grande política da linguagem. Rio de Janeiro: Civilização Brasileira, 2005.

SANTI, P. L. R. de. A construção do eu na modernidade: da Renascença ao século XIX. Ribeirão Preto: Holos, 1998. 